\title{
The Diagnostic Accuracy of Endometrial Sampling in Endometrial Hyperplasia
}

\author{
Serdar BAŞARANOĞLU ${ }^{1}$, Elif AĞAÇAYAK ${ }^{2}$, Şafak HATIRNAZ ${ }^{1}$, Ayşegül DEREGöZÜ ${ }^{3}$, Mustafa ACET ${ }^{4}$ \\ Ebru YÜCE5 ${ }^{5}$ Talip KARAÇOR ${ }^{2}$, Mehmet Sait İÇEN², Mehmet Sıddık EVSEN², Talip GÜL² \\ Istanbul, Turkey
}

\begin{abstract}
OBJECTIVE: Endometrial hyperplasia is a premalignant lesion characterized with hyperplastic changes in endometrial gland and stromal structures. Its incidence is not exactly known. This study evaluated the accuracy of endometrial sampling of the patients whose pathological results were endometrial hyperplasia and had undergone hysterectomy (paraffin sections).

STUDY DESIGN: Patients that diagnosed with endometrial hyperplasia by endometrial biopsy and/or hysterectomy at Dicle University School of Medicine Department of Obstetrics and Gynecology between January 2006 and July 2014 were retrospectively evaluated. Sensitivity, specificity, and positive and negative predictive values of endometrial biopsy to predict postoperative hysterectomy result were calculated. Discrete results in endometrial sampling and hysterectomy were recorded separately. Statistical analyses were conducted with corresponding appropriate methods.
\end{abstract}

RESULTS: Mean ages of pre and postmenopausal patients were $42.6 \pm 4.8(28-50)$ and $57.7 \pm 7.7$ (5079) years, respectively. For the efficiency of endometrial sampling to predict definite pathologic diagnosis, sensitivity was $71.9 \%$, specificity was $87.5 \%$, positive predictive value was $79.3 \%$, and negative predictive value was $82.3 \%$. When the accuracy of endometrial sampling with the pathologic diagnosis was evaluated, 38 patients had accurate $(47.5 \%)$, and 42 patients had discrete $(52.5 \%)$ results.

CONCLUSION: The presence of atypia determines the treatment in patients with endometrial hyperplasia. Hysterectomy should not be the first option in endometrial hyperplasia patients without atypia, and medical treatment and curettage options should be considered. Experienced staff should perform and evaluate endometrial samplings. We consider that this will increase the success in diagnosis, and could change treatment options.

Keywords: Endometrium, Hyperplasia, Curettage, Hysterectomy, Diagnostic disagreement

Gynecol Obstet Reprod Med 2017;23(1):37-40

${ }^{1}$ Bilge Hospital Department of Obstetrics and Gynecology, Istanbul

${ }^{2}$ Dicle University Faculty of Medicine Department of Obstetrics and Gynecology, Diyarbakır

${ }^{3}$ Bahçelievler State Hospital Department of Obstetrics and Gynecology, Istanbul

${ }^{4}$ Medipol University Faculty of Medicine Department of Obstetrics and Gynecology, Istanbul

${ }^{5}$ Akropol Hospital Department of Obstetrics and Gynecology, Ankara

Address of Correspondence: Serdar Başaranoğlu

Bilge Hospital, Department of Obstetrics and Gynecology, Istanbul

drsbasaran@gmail.com.tr

Submitted for Publication: $\quad 26.09 .2016$

Accepted for Publication: $\quad$ 15.02.2017

\begin{tabular}{|c|c|}
\hline & Access this article online \\
\hline $\begin{array}{c}\text { Quick Response Code: } \\
\text { Website: www.gorm.com.tr }\end{array}$ & DOI:10.201613/GORM.2016.635 \\
\cline { 2 - 3 } & \\
\hline
\end{tabular}

How to cite this article: Başaranoğlu S. Ağaçayak E. Deregözü A. Acet M. Yüce E. Karaçor T. The Diagnostic Accuracy of Endometrial Sampling in Endometrial Hyperplasia . Gynecol Obstet Reprod Med 2017;23(1):37-40

\section{Introduction}

Endometrial hyperplasia (EH) is a proliferation characterized with increased gland/stroma proportion in glandular and stromal structures of uterine cavity. Its exact incidence is not known, but it is seen in $1.5-15 \%$ of abnormal uterine bleeding (AUB), and $5 \%$ of hysterectomy specimens. Diagnosis is based on variations in sizes of endometrial glands; abnormal proliferation characterized with irregular shapes, and decreased stromal content. Wide-ranged and heterogeneously characterized abnormal proliferations are also precancerous lesions of endometrial carcinoma (1). Endometrial hyperplasia is categorized in four groups according to glandular structure and presence of nuclear atypia as without simple/complex atypia (2). Nuclear atypia is the most important risk factor for cancer progression. Cancer risk in untreated patients ranges between $1 \%$ and $29 \%$ (3). Kurman et al. established a classification of endometrial hyperplasia based on 1994 classification of World Health Organization (WHO). Besides being a precancerous lesion, endometrial hyperplasia has also clinical importance for causing AUB (4). In many centers, endometrial 
sampling is performed to eliminate a potential endometrial malignancy to patients that should go under hysterectomy. Previous studies reported that endometrial sampling has high false-negativity rates $(5,6)$.

The aim in this study is to evaluate the accuracy of endometrial sampling of the patients whose pathological results were endometrial hyperplasia and had undergone hysterectomy (paraffin sections).

\section{Material and Method}

Patients with a diagnosis of $\mathrm{EH}$ in endometrial biopsy and/or hysterectomy specimens (paraffin sections) between January 2006 and July 2014 in Dicle University Medical Faculty Gynecology and Obstetrics Department were retrospectively evaluated. A total of 261 patients had an EH diagnosis in this period, which included all subtypes (with/without atypia, simple/complex). Patient's data were obtained from hospital records in archives and electronic databases. Different gynecological causes (leiomyoma, adenomyosis, endometriosis, pelvic organ prolapse, chronic pelvic pain, invasive and/or pre-invasive diseases of cervix uteri, and adnexal malignancies) and patients with missing parameters were excluded from the study. After exclusions, 80 patients with a diagnose compatible with $\mathrm{EH}$ in at least one evaluation were included. Age, operations, menopausal state, endometrial biopsy result, and post-hysterectomy pathologic evaluation result were recorded. Sensitivity, specificity, and positive and negative predictive values of endometrial biopsy for predicting lesions in postoperative hysterectomy specimens (paraffin sections) were calculated as seen in table 1. Discordant results between endometrial sampling and hysterectomy materials were reported separately. Endometrial sampling was performed with suction curettage to all of the patients.

Statistical Package for Social Sciences for Windows 15.0

Table 1: Pathology results were compared with / without atypia
(SPSS Inc., Chicago, IL, USA) and Microsoft Office Excel (Microsoft Inc., USA) were used for the statistical evaluations. Normal distribution of numerical data was assessed with Kolmogorov-Smirnov test, and presented as mean and standard deviations. Normally distributed parameters were analyzed with Student-t test. Analyze results were considered statistically significant when $\mathrm{p}<0.05$ in $95 \%$ confidence interval. Local ethical committee of Dicle University approved the study.

\section{Results}

Our hospital is a reference center in Southeastern Anatolian Region. Of the patients who had hysterectomy, 53 $(66.3 \%)$ were premenopausal, and $27(33.7 \%)$ were postmenopausal patients. Mean ages of pre and postmenopausal patients were $42.6 \pm 4.8$ (28-50) years, and 57.5 \pm 7.7 (50-79) years, respectively. Pathologic results as endometrial polyp, secretory endometrium, proliferative endometrium, irregular endometrium, adenomyosis, atrophic endometrium or endometrium with gestagenic effect were considered as endometrial samples without atypia. For the efficiency of endometrial sampling to predict exact pathological diagnosis, sensitivity was $71.9 \%$, specificity was $87.5 \%$, positive predictive value was $79.3 \%$, and negative predictive value was $82.3 \%$ (Table 2). When the accuracy of final pathology reports and endometrial sampling was considered, 38 patients (47.5\%) had accordant results, but 42 patients (52.5\%) had discordant results (Table 3 ). All of the endometrial biopsy and hysterectomy specimens' (paraffin sections) materials were evaluated in the same department. The results of endometrial sampling were discordant with the results of hysterectomy in 21 patients. All patients had total abdominal hysterectomy (TAH), and menopausal patients had bilateral salpingooophorectomy (BSO) additionally. One case operated due to complex atypical hyperplasia in endometrial sampling was reoperated due to final pathological diagnosis of endometrial adenocarcinoma.

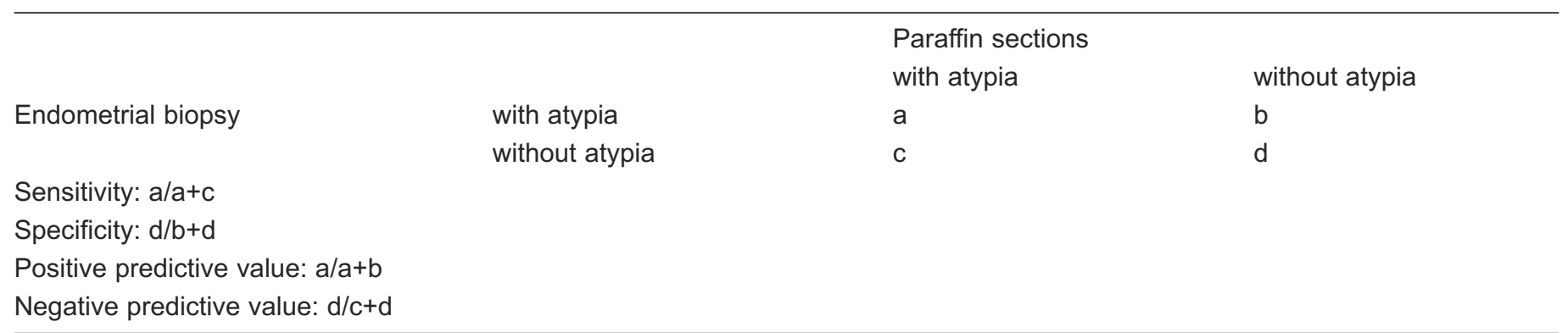

Table 2: Pathology results were compared with / without atypia

\begin{tabular}{lcccc}
\hline \multicolumn{1}{c}{$\mathrm{n}$} & Sensitivity & Specificity & $\begin{array}{c}\text { Pozitive } \\
\text { predictive value }\end{array}$ & $\begin{array}{c}\text { Negative } \\
\text { predictive value }\end{array}$ \\
\hline Menopause (27) & 72.7 & 87.5 & 80 & 82.3 \\
Reproductive period (53) & 71.4 & 87.5 & 78.9 & 82.3 \\
All patients (80) & 71.9 & 87.5 & 79.3 & 82.3 \\
\hline
\end{tabular}


Table 3: Comparing the final pathology after endometrial sampling and hysterectomy

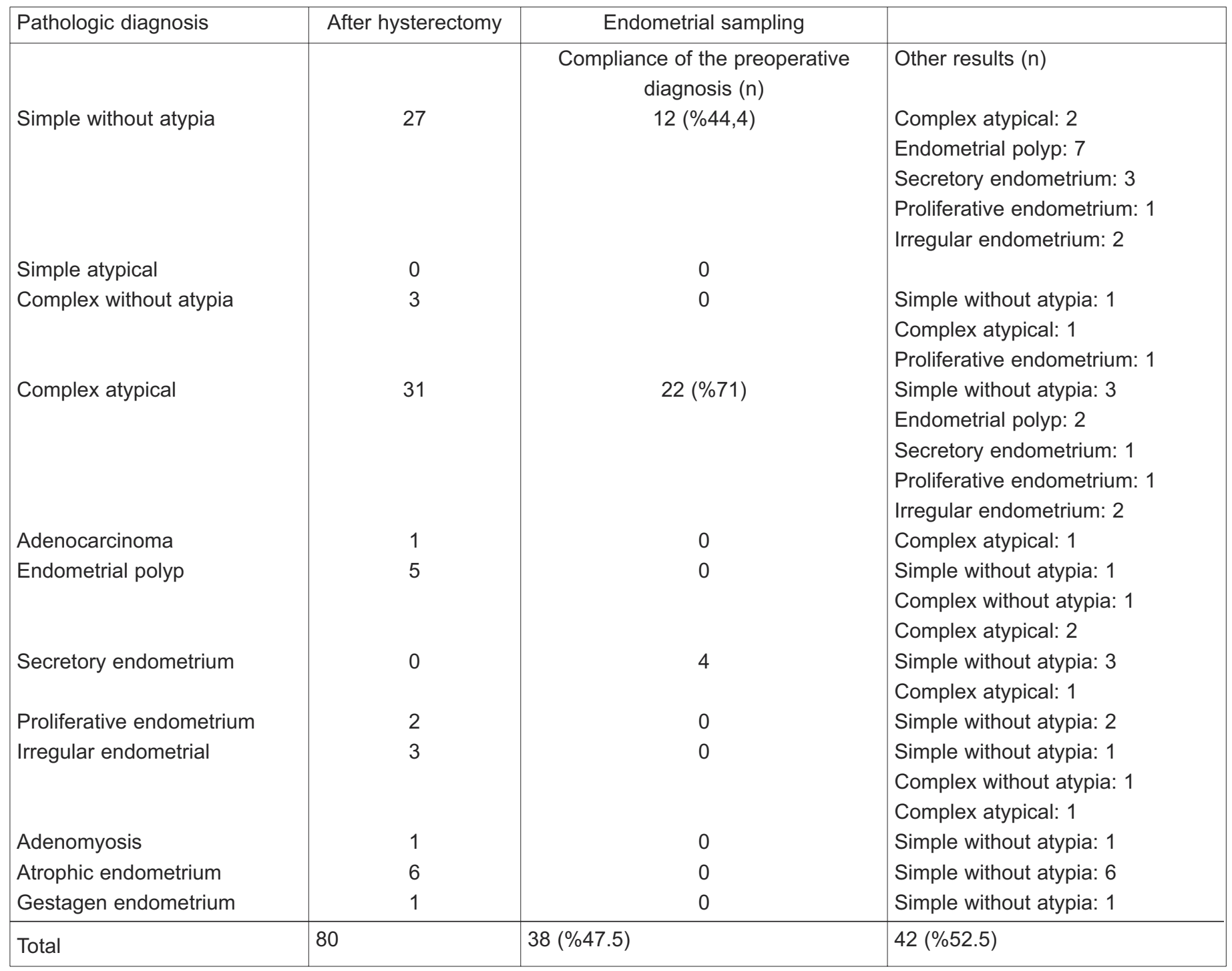

\section{Discussion}

Abnormal uterine bleeding can be seen in every age during reproductive period, and it is one of the most frequent complaints for gynecological admissions. The underlying pathological cause is frequently benign, but it can be a sign for a premalignant/malignant lesion particularly in menopausal period (7). Today, there are many non-invasive diagnostic methods for determining the pathologies causing AUB. These methods are limited for evaluating uterus and endometrium, and many pathological conditions are gone unnoticed (8). Endometrial hyperplasia is a pathological condition characterized with hyperplastic changes in endometrial stroma and glands (9). Etiology of AUB is not completely known, but many factors play role. These are polycystic ovary syndrome (chronic anovulation), nulliparity, early menarche, delayed menopause (>55), unmet (without progesterone) estrogen replacement therapy (ERT), obesity, tamoxifen use, and estrogen secreting ovarian tumors $(10,11)$. Endometrial pathologies are frequently seen in perimenopausal women (50-54 years) with early symptoms, but rarely seen under age 30 (12). They are commonly diagnosed with endometrial biopsy, curettage, or post-hysterectomy (13). Differential diagnosis should include irregular proliferative endometrium, polyps, tubal metaplasia, cystic atrophy, and endometrial glandular-stromal destruction. Endometrial sampling is considered as standard method to evaluate endometrial pathologies, but there are studies for and against its utilization in benign conditions (uterine myoma, prolapse, etc.) $(14,15)$. Endometrial sampling prior to routine hysterectomy was not recommended for asymptomatic patients with low risk for endometrial carcinoma, but recommended for patients $\geq 35$ years of age with AUB or postmenopausal bleeding, or patients $<35$ years of age with high risk (5). Prediction rates of postoperative pathological result in patients with a diagnosis of $\mathrm{EH}$ in endometrial sampling ranges from $6.3 \%$ to $72.2 \%$. Gundem et al. showed in their study that pre- and postoperative endometrial results were not statistically correlated (16). However Saygili et al. reported statistically significant results in their study of patients with postmenopausal bleeding and that evaluated endometrial thickness (17). When we considered benign endometrial findings (endometrial polyp, proliferative endometrium, irregular endometrium, adenomyosis, 
atrophic endometrium, and endometrium on gestagenic effect) as without atypia, sensitivity, specificity, and positive and negative predictive values of pre- and post-menopausal women were similar (Table 1). In case where atypia is well discriminated the success of pathological diagnosis is higher. Patients with EH without atypia can be treated with progestin or dilatation and curettage (18). Moreover, EH with atypia has adenocarcinoma risk up to $25 \%$ (19). In our study, we observed that $12(40 \%)$ of 30 patients with EH without atypia (simple+complex) had preoperative accordant results. This was $71 \%$ for patients with EH with atypia, and $47.5 \%$ when all patients combined. Endometrial sampling result is more prone to be without atypia in benign conditions like endometrial polyp, secretory endometrium, proliferative endometrium, irregular endometrium, adenomyosis, atrophic endometrium, and endometrium on gestagenic effect (20). Spontaneous regression possibility and the curative effect of curettage plays role in the low success rate of endometrial sampling in patients with EH without atypia. Preoperative diagnosis rates in patients with EH with atypia are close to best rates in the literature $(6.3 \%$ $72.2 \%$ ). Different pathologists, sampling method of endometrial material, and experience of the surgeons, might relate the limited success rates to evaluation of materials.

In conclusion, Hysterectomy should not be considered as the first choice of treatment in EH without atypia and medical treatment and therapeutic curettage should be taken into consideration. We conclude that endometrial sampling performed preferably in the experienced hands and samples evaluated by the experienced pathologists will increase the diagnostic accuracy and will change the treatment modalities towards less invasive modalities.

\section{References}

1. Kurman RJ, McConnell TG. Precursors of endometrial and ovarian carcinoma. Virchows Arch 2010 Jan;456(1):1-12.

2. Silverberg SG, Kurman RJ, Nogales F. Epithelial tumors and related lesions of endometrium. In: FA Tavassoli, MR Stratton, editors. Tumors of the Breast and Female Genital Organs. Lyon: IARC Press 2003:221-32.

3. Kurman RJ, Kaminski PF, Norris HJ. The behavior of endometrial hyperplasia. A long-term study of 'untreated' hyperplasia in 170 patients. Cancer 1985 Jul 15;56(2):403-12.

4. Cavanagh D, Fiorica JV, Hoffman MS, Durfee J, Nicosia SV. Adenocarcinoma of the endometrium: An institutional review. Cancer Control 1999 Jul;6 (4):354-60.

5. Stovall TG, Soloman SK, Ling FW. Endometrial sampling prior to hysterectomy. Obstet Gynecol 1989 Mar;73 (3 Pt 1):405-9.

6. Stever MR, Farmer G, Hernandez E, Miyazawa K. Routine prehysterectomy endometrial biopsy in a series of 523 women. J Am Osteopath Assoc 1986 Sep; 86 (9):558-60.

7. Butlerand JW, Carnovale DE. Section V, Surgery for Benign Gynecologic Conditions. In: Te Linde's operative gynecology. $10^{\text {th }}$ Edition, Philadelphia: Lippincott-Raven 2008;585-608.

8. Yumuşak ÖH, Erkılınç S, Kahyaoğlu S, Erkaya S, Şenyurt H. Evaluation of The Diagnostic Accuracy of Endometrial Sampling Before Hysterectomy. JGON 2014;11(3):97100.

9. Baak JP, Qrbo A, van Diest PJ, Jiwa M, de Bruin P, Broeckaert M, et al. Prospective multicenter evaluation of the morphometric D-score for prediction of the outcome of endometrial hyperplasias. Am J Surg Pathol $2001 \mathrm{Jul}$; 25(7):930-35.

10. Ricci E, Moroni S, Parazzini F, Surace M, Benzi G, Salerio B, et al. Risk factors for endometrial hyperplasia: results from a case-control study. Int J Gynecol Cancer 2002 May-Jun;12(3):257-60.

11. Horn LC, Meinel A, Handzel R, Einenkel J. Histopathology of endometrial hyperplasia and endometrial carcinoma: an update. Ann Diagn Pathol 2007 Aug;11(4):297-311.

12. Reed SD, Newton KM, Clinton WL, Epplein M, Garcia R, Allison $\mathrm{K}$, et al. Incidence of endometrial hyperplasia. Am J Obstet Gynecol 2009 Jun; 200 (6):678.e1-6.

13. Allison KH, Reed SD, Voigt LF, Jordan CD, Newton KM, Garcia RL. Diagnosis endometrial hyperplasia: why is it so difficult to agree? Am J Surg Pathol 2008 May;32(5): 691-8.

14. Çakmak B, Nacar MC, Aysal T, Hısım Y, Demirtürk F. The Evaluation Of Hysterectomy Cases Performed For Benign Indications In Our Clinic. Gaziosmanpaşa Üni Tıp Fak Derg 2013;5(2):78-83.

15. Ercan Ö, Demir S, Dede S. Benign Nedenlerle Yapılan Histerektomi Olgularında Histerektomi Öncesi Endometrial Örnekleme ve Histerektomi Sonrası Patoloji Sonuçlarının Karşılaştırılması. Ortadoğu Medical Journal 2013; 5(4):190-93.

16. Gundem G, Sendag F, Kazandi M. Preoperative and postoperative correlation of histopathological findings in cases of endometrial hyperplasia. Eur J Gynaecol Oncol 2003; 24 (3-4):330-3.

17. Saygili H. Histopathologic correlation of dilatation and curettage and hysterectomy specimens in patients with postmenopausal bleeding. Eur J Gynaecol Oncol 2006;27 (2):182-4.

18. Sivridis E, Giatromanolaki A Prognostic aspects on endometrial hyperplasia and neoplasia. Virchows Arch 2001 Aug; 439 (2):118-26.

19. Tavassoli F, Kraus FT Endometrial lesions in uteri resected for atypical endometrial hyperplasia. Am J Clin Pathol 1978 Nov; 70(5):770-9.

20. Budak MŞ, Şentürk MB, Akgöl S, Obut M, Tahaoğlu AE, Toğrul C, et al. Evaluation of the Relationship Between Histopathological Tissue Diagnosis and Endometrial Thickness in Cases with Postmenopausal Bleeding. Gynecol Obstet Reprod Med 2016;21(2):81-85 